\title{
PERANCANGAN BRAND IDENTITY DAN MEDIA NAWTELLA UNTUK MENINGKATKAN BRAND AWARENESS
}

\author{
Annisa Alifia ${ }^{1}$, Sultan Arif Rahmadianto ${ }^{2}$, Bintang Pramudya P. P 3 \\ Program Studi Desain Komunikasi Visual, Universitas Ma Chung \\ Email :331510002@student.machung.ac.id, sultan.arif@machung.ac.id, \\ bintang.pramudya@machung.ac.id
}

\begin{abstract}
Abstrak
Peran UMKM dalam perekonomian Indonesia tak kalah penting dengan sektor-sektor industri lainnya. Data dari Kementrian Koperasi dan UMKM RI pada tahun 2017 melaporkan bahwa secara jumlah unit, UMKM memiliki pangsa sekitar 99,99\% (62,9 juta unit) dari total keseluruhan pelaku usaha di Indonesia. (Haryanti dan Hidayah, 2018). Dengan diiringi kemajuan teknologi, para pengusaha UMKM menemukan kemudah untuk memulai dan mengembangkan usaha yang dimiliki. Nawtella adalah salah satu UMKM yang menjual produk makanan ringan akan tetapi perusahaannya masih kurang dikenali oleh masyarakat. Oleh karena itu, dilakukannya perancangan ini dengan menggunakan metode kualitatof. Hasil dari perancangan ini adalah logo, buku CIS, kemasan, serta konten untuk lama Instagram.
\end{abstract}

Kata Kunci: logo, branding, Instagram, cookies, media promosi digital.

\section{Abstract}

Home-based business role in Indonesia's economy has been showing a big growth in these late couple of years. Ministry of Koperasi an UMKM released a collective data in the year 2017. They pointed that small and home-based businesses in Indonesia are approximately around 62,9 million units. (Haryati and Hidayah, 2018). Technology and economy growth are always beneficial to one another and in this case, all the units and people could gain profit from it, such as the increasing amount of platforms and mobile applications which offer them to advertise their products and services. Nawtella is one of the home-based industry in West Jakarta. Nawtella mainly sells are home-made cookies but their brans isn't popular among people in West Jakarta. Therefore, this project is done by qualitative methods and has purpose to create a brand identity which includes logo, CIS, packaging, and feeds for their Instagram page.

Keywords: logo, branding, Instagram, cookies, digital promotion

\section{PENDAHULUAN}

Peran UMKM dalam perekonomian Indonesia tak kalah penting dengan sektor-sektor industri lainnya. Dalam kehidupan sehari-hari masyarakat, peran UMKM juga sangat membantu. Data dari Kementrian Koperasi dan UMKM RI pada tahun 2017 melaporkan bahwa secara jumlah unit, UMKM memliki pangsa sekitar 99,99\% (62,9 juta unit) dari total keseluruhan pelaku usaha di Indonesia. (Haryanti dan Hidayah, 2018). Dalam 5 tahun terakhir, makanan dan minuman menjadi marak didirikan oleh masyarakat karen akemajuan teknologi saat ini, salah satunya adalah sebuah aplikasi jasa yang merangkup pengantaran makanan dan minuman. Riset yang dilakukan oleh Lembaga
Demografi Fakultas Ekonomi dan Bisnis Universitas Indonesia (LD FEB UI, 2018), kontribusi layanan transportasi online terhadap perekonomian Indonesia melakui UMKM pada tahun 2017 menunjukan (1) 26\% mitra UMKM mengalami peningkatan volume transaksi setelah menjadi mitra aplikasi jasa online, (2) 76\% mitra UMKM mengalami peningkatan volume transaksi diatas $10 \%$ dan (3) 100 responsen UMKM mendapatkan pelanggan baru sejak bergabung dengan jasa transportasi online. Presentase UMKM di DKI Jakarta mencapai 98,78 persen dari total jumlah usaha di DKI Jakarta. Kota Jakarta Barat masih menjadi konsentrasi UMKM dengan jumlah UMKM sekitar 305 usaha ata mencapai lebih besar dari 26 persen. (BPS DKI Jakarta, 2016). Nawtella adalah salah satu UMKM yang ada di Kota Jakarta. Nawtella dikategorikan dalam UMKM pangan yang fokus produknya adalah makanan ringan buatan rumah atau homemade. Nama Nawtella terinspirasi dari produk selai cokelat kacang, karena salah satu bahan dasar dari pembuatan cookies yang ditawarkan oleh Nawtella.

\section{TINJAUAN PUSTAKA}

Sianturi (2020) dalam judul "Perancangan Desain Logo Toko "Super Bakery" dan Pengaplikasiannya", tujuan perancangan ini adalah pembuatan logo yang nantinya akan diaplikasikan pada bon faktur, paper bag, signange, kemasan produk dan merchandise yang berbentuk kaos, kemeja, jam dinding, payung dan topi. Dari artikel ilmiah tersebut, didapatkan masukan bagi perancangan yang dilakukan berupa : 1) Metode perancangan; 2) Jenis-jenis merchandise yang dibuat. Seloadji, dkk (2018) dalam judul "Perancangan Corporate Identity VIP Bakery Tulungagung", penelitian ini bertujuan untuk membuat corporate identity untuk VIP Bakery sehingga memiliki kesan positif dan terpercaya oleh masyarakat Tulungagung. Dari artikel ilmiah tersebut, didapatkan masukan bagi perancangan yang dilakukan berupa : 1) Metode analisis berupa SWOT; 2) Pengaplikasian corporate identity yang luas; 3) Penerapan unsur ikonik sebagai bentuk pembeda identitas yang khas.

Tandio, dkk (2013) dalam judul "Perancangan Logo dan Desain Kemasan Untuk Dhisti Cookies Sebagai Camilan di Kota Solo", tujuan penelitian adalah pembuatan logo dan desain kemasan yang bervariasi serta interaktif. Dari artikel tersebut, didapatkan masukan bagi perancangan yang dilakukan berupa : 1) Metode analisis; 2) Logo yang memberikan identitas yang jelas; 3) Perancangan desain kemasan yang dibuat sebagai sarana media promosi tidak langsung. 
Indika dan Jovita (2017) dalam judul "Media Sosial Instagram Sebagai Sarana Promosi Untuk Meningkatkan Minat Beli Konsumen", tujuan dari penelitian ini adalah meneliti bagaimana media sosial Instagram mempengaruhi minat beli konsumen. Dari artikel tersebut, didapatkan masukan bagi perancangan yang dilakukan berupa, media sosial Instagram mempunyai peran penting dan kuat sebagai sarana promosi produk.

Rustandi (2018) dalam judul "Implementasi Digital Marketing dalam Membangun Brand Awareness", tujuan dari penelitian adalah membangun brand awareness dan medi apromosi yang dibentuk menggunakan digital marketing. Dari artikel tersebut, didapatkan masukan bagi perancangan yang dilakukan berupa metode penelitian menggunakan informas, studi kepustakaan, wawancara, dan observasi.

Halim, dkk (2019) dalam judul "Perancangan Brand Identity E-Commerce "Greater Good"", tujuan dari penelitian ini adalah perancangan brand identity dan media pendukung identitas berupa stationery, packaging, website serta media sosial guna meningkatkan brand awareness terhadap brand. Dari artikel tersebut, didapatkan masukan bagi perancangan yang dilakukan berupa : 1) Metode perancangan; 2) Metode analisis SWOT; 3) Penggunaan brand strategy, brand communication, visual branding.

\section{METODE PERANCANGAN}

Metode perancangan yang digunakan adalah perancangan kualitatif dengan tahapan perancangan yaitu pengumpulan data berupa wawancara dan dokumetasi. Data yang diperoleh akan diproses dalam analisis data dan sintesis konsep menggunakan metode SWOT (Strengths, Weakness, Opportunities, Threats), dan dilanjutkan dengan tahap visualisasi. Tahap visualisasi terdiri dari beberapa tahapan yaitu pembuatan thumbnail, rough sketch, comprehensive sketch, dan final design.

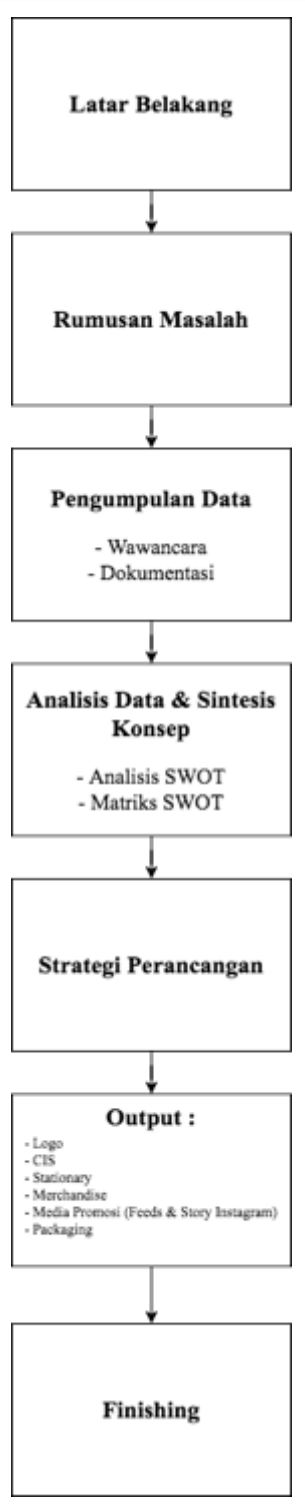

Gambar 1. Bagan Alir Perancangan

\section{HASIL DAN PEMBAHASAN}

\subsection{Pengumpulan dan Analisis Data}

Perancangan logo dan media promosi Nawtella membutuhkan informasi tentang perusahaan serta produk yang dijual. Berdasarkan data yang dikumpulkan, dilakukan analisis data SWOT yang melingkupi internal perusahaan serta eksternal perusahaan.

\subsection{Analisis Data}

Analisis dari data-data yang didapatkan dan dianalisis, diolah kembali ke dalam matriks SWOT Matriks SWOT adalah alat untuk menyusun faktor-faktor strategis organisasi yang dapat menggambarkan secara jelas peluang, ancaman, kekuatan dan kelemahan yang dimiliki. Strategi tersebut adalah strategi SO, strategi WO, strategi ST, dan strategi WT. (Fatimah, 2016, pp. 28).

Berdasarkan analisis SWOT yang telah dilakukan, Nawtella mempunyai permasalahan pada tidak adanya identitas brand yang menarik. Oleh karena itu, diperlukannya pembuatan identitas brand yang dapat meningkatkan brand awareness 
konsumen terhadap perusahaan sehingga dapat menarik perhatian dari target pasar dengan melalui visual yang ditampilkan.

\subsection{Sintesis Konsep Perancangan}

Nawtella dirancang dengan gaya desain yang simpel, minimalis dan natural dengan tetap menampilkan kesan yang fun, personal, intimate dan natural.

Perancangan warna identitas Nawtella terdiri dari warna kuning sebagai warna tama dan warna merah, hitam dan cokelat sebagai warna pendukung. Seluruh warna akan diterapkan pada semua media visual seperti logo, media promosi, dan media pendukung seperti merchandise dan stationery. Hal ini diperuntukkan agar brand identity dari Nawtella bersifat konsisten. media sosial berupa Instagram. Instagram adalah media sosial yang efektif bagi Nawtella untuk melakukan promosi karena penggunaannya yang mudah serta dapat dilakukan dimana saja. Selain penggunaan media sosial, pembuatan kemasan produk digunakan sebagai media promosi lain untuk brand.

\subsection{Visualisasi Desain}

Perancangan visual untuk re-branding Nawtella mempunyai tahapan-tahapan yang akan dilakukan yaitu, perancangan logo, penentuan tipografi dan warna identitas, buku Corporate Identity System (CIS) dan media promosi digital melalui Instagram. Pada setiap tahap visual akan dilakukan dengan membuat thumbnail, rough sketch dan comprehensive. Setiap proses tersebut yang dilakukan akan menggunakan teori layout, grid, sehingga visual yang dihasilkan maksimal.

Identitas visual yang telah dibuat akan dimasukkan ke dalam buku Corporate Identity System (CIS) yang bertujuan untuk menjadi panduan dalam menggunakan dan mengaplikasikan logo dan elemen-elemen identitas kepada berbagai media seperti corporate identity, merchandise, stationary dan kemasan. Proses selanjutnya akan dilakukannya proses pengambilan foto produk untuk kebutuhan media promosi yang akan dilakukan. Foto yang terpilih akan melalui proses editing sehingga seragam dengan keseluruhan gaya desain perancangaan.

\subsubsection{Logo}

Thumbnail logo yang dibuat digunakan sebagai panduan atau pilihan yang berisi beberapa logo. Thumbnail yang dibuat pada tahap ini mengambil nama perusahaan yaitu Nawtella, produk yang dijual yaitu cookies dan gender pemilik perusahaan yaitu perempuan sebagai mascot.

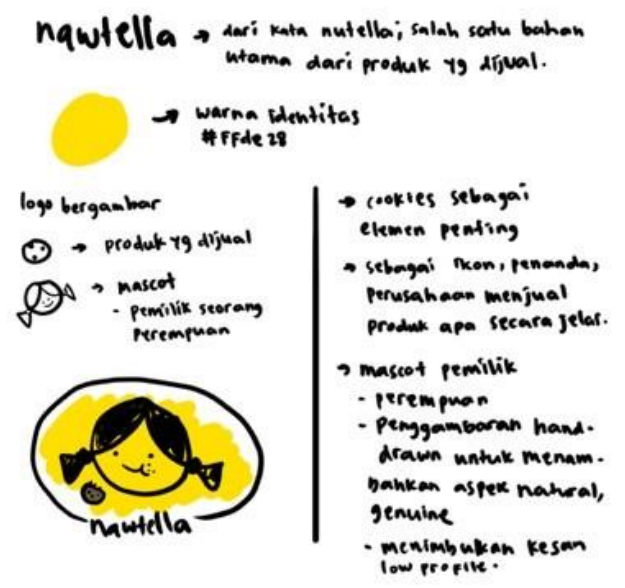

Gambar 2. Thumbnail Logo
Rough sktech yang dibuat akan sesuai dengan thumbnail yang telah dibuat. Logo akan menampilkan produk yang dijual, nama perusahaan dan mascot. Dalam rough sketch ini juga dilakukan beberapa pilihan logo yang salah satunya akan dipilih dan lalu diolah secara digital sehingga menghasilkan logo yang rapi dan konsisten.

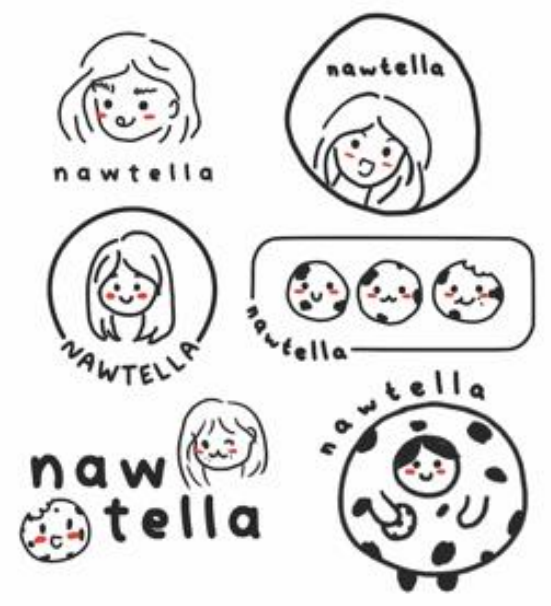

Gambar 3. Rough Sketch Logo

Dengan 6 pilihan yang sudah dibuat pada rough sketch, pada tahap ini dipilihlah satu logo yang dianggap paling sesuai dengan tujuan dan citra brand. Logo yang dipilih digambarkan anak perempuan menggunakan kostum cookies dan sedang mengenggam sebuah cookies.
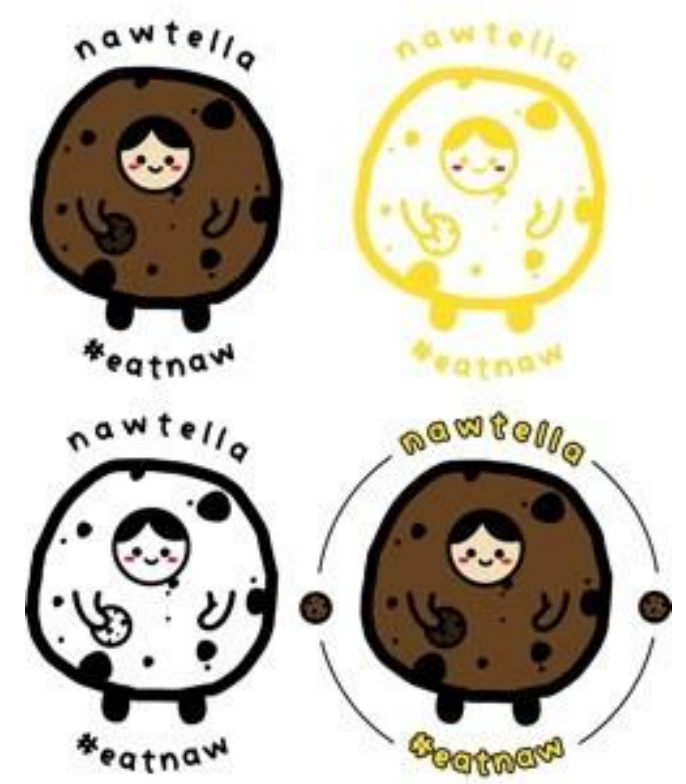

Gambar 4. Comprehensive Logo

Logo mempunyai peran penting dalam sebuah brand dan dalam meningkatkan brand awareness, logo digunakan untuk menarik perhatian target audiens. Logo yang telah dipilih mempunyai dua jenis logo yaitu logogram dan logotype. 


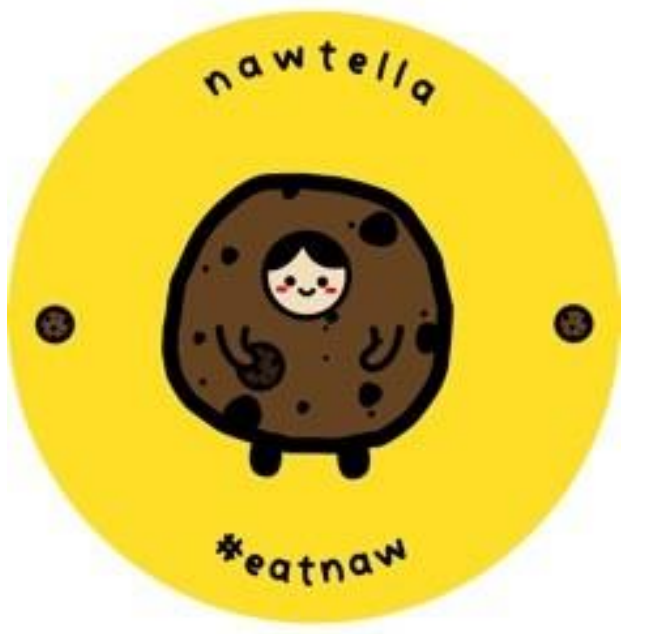

Gambar 5. Logo Final

Logo yang sudah dipilih dan disetujui akan diolah menjadi motion agar memberikan kesan fun dan dapat dengan mudah dipadukan dengan video brand. Motion yang dirancang menggerakan logogram seakan-akan berjalan.

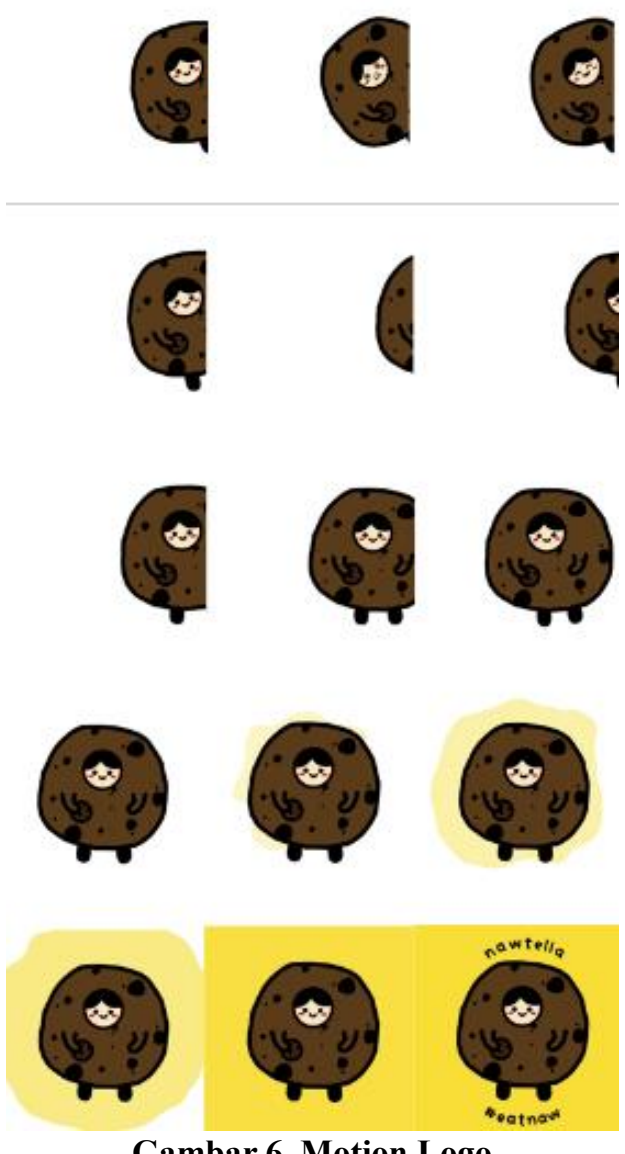

Gambar 6. Motion Logo

\subsubsection{Tipografi}

Tipografi yang akan digunakan adalah font "Vividly" yang berjenis hand-written, sans-serif. Font ini akan diterapkan pada setiap headline, title, dan juga ada berada dalam logo. Sedangkan untuk sub-headline dan body copy akan menggunakan font "Jost" yang juga berjenis sans-serif.

\section{Aa Aa Aa Aa Aa \\ Vividly Jost Regular Jost ltalic Jost Medium Jost Bold}

\section{Gambar 7. Tipografi}

\subsubsection{Color Palette}

Warna mempunyai peran penting dalam sebuah brand identity dan juga dalam mengingkatkan brand awareness dari brand tersebut. Selain itu, warna juga dapat menjadi sebagai pembeda brand dengan brand lainnya. Pemilihan warna yang tepat akan mempengaruhi gambaran brand di mata konsumen karena setiap warna memiliki kesan dan arti yang berbeda-beda. (Wheeler, 2009, pp. 128) .

Warna yang digunakan dalam perancangan ini adalah warna kuning, coklat, hitam dan merah. Warna kuning dan merah bertujuan untuk menarik perhatian, memberikan kesan fun dan uplifting. Warna coklat digunakan untuk memberikan kesan penyeimbang sedangkan pemilihan warna hitam digunakan untuk memberikan kesan profesional dan elegan. Warna-warna tersebut akan digunakan pada setiap identitas visual brand yaitu pada logo, pattern, kemasan dan media lainnya.
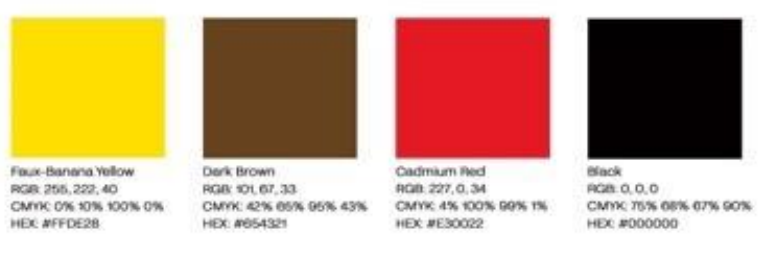

\section{Gambar 8. Color Palette}

\subsubsection{Pattern}

Pattern yang telah dibuat menggunakan garis yang berujung bulat sesuai dengan garis yang diterapkan pada logo. Hal ini dilakukan agar identitas visual yang dihasilkan konsisten. Perancangan elemen pattern diambil dari nilai dan citra dari Nawtella yaitu personal, intimate, natural, fun, dan sincere. Berawal dari kata-kata tersebut, desainer mencari sinonim dan relasi-relasi sehingga setiap kata dapat tergambar pada pattern.

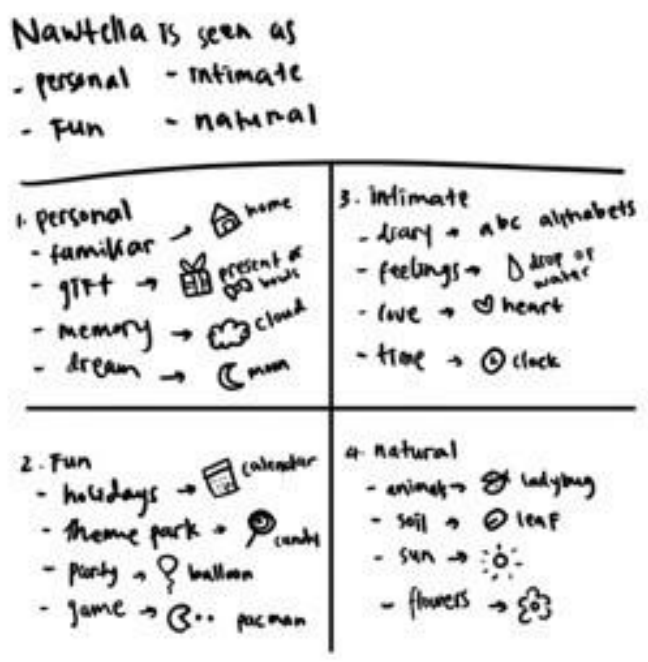




\section{Gambar 9. Thumbnail Pattern}

Dengan terkumpulnya sinonim dan relasi dari kata-kata tersebut, maka dirancangnya penataan dan ikon-ikon yang dipilih untuk pattern yang akan dibuat. Setiap ikon yang digambar memiliki makna tersendiri.

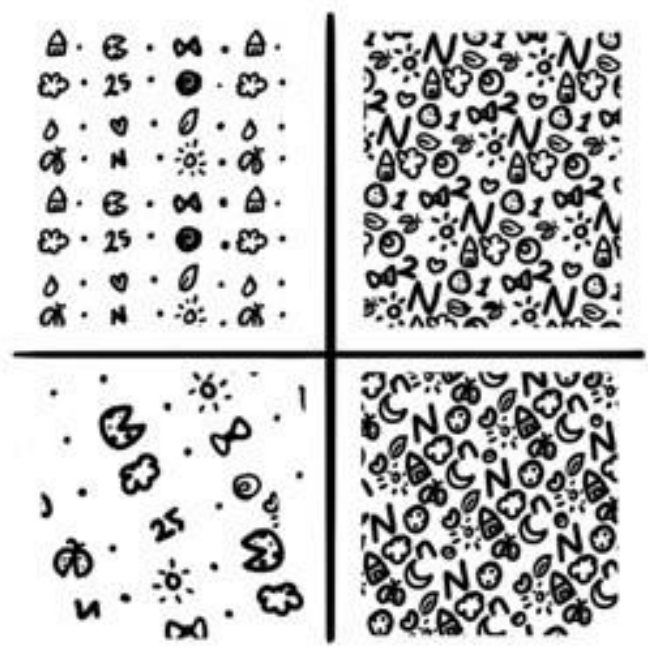

Gambar 10. Rough Sketch

Proses yang dilakukan setelah thumbnail dan rough sketch adalah pembuatan comprehensive. Penyusunan ikon-ikon dalam pattern dibuat lebih rapi dan menyatu sehingga saat diterapkan pengulangan tidak berantakan dan dapat menjadi kesatuan pattern yang dapat diterapkan dalam media identitas visual.

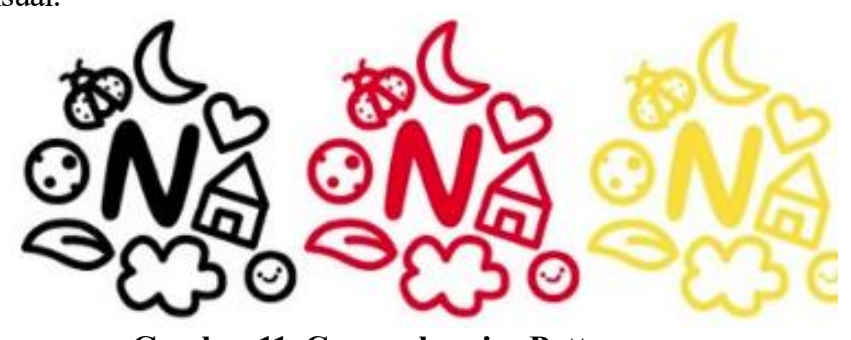

Gambar 11. Comprehensive Pattern

Pattern yang sudah dibuat dalam tahap comprehensive disusun ke samping secara berulang dalam beberapa baris. Penyusunan pattern dibuat senatural mungkin agar terlihat seperti doodle atau coretan.

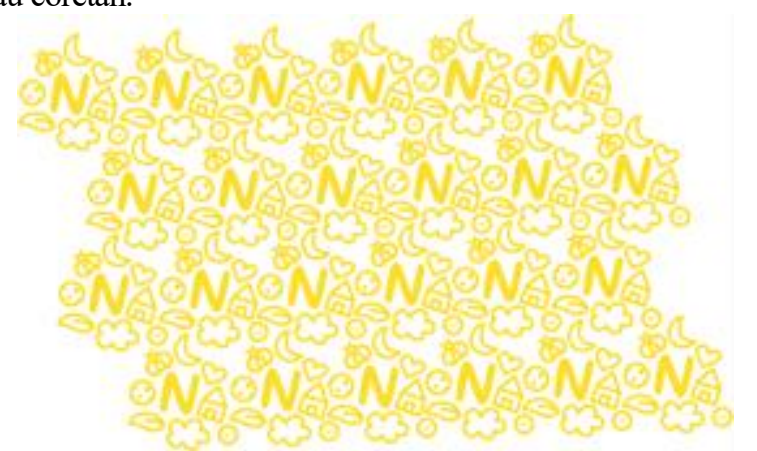

Gambar 12. Final Pattern

\subsubsection{Kemasan}

Kemasan yang dirancang akan mempunyai bentuk yang sederhana dan menggunakan bahan yang ramah lingkungan. Bahan yang akan digunakan yaitu kertas sedangkan bentuk dari kemasan adalah sebuah toples atau paper bowl. Rough sketch perancangan ditentukan oleh bentuk dan ukuran kemasan. Ukuran kemasan disesuaikan dengan jumlah cookies yang dipesan. Ada 2 kemasan ukuran kemasan dalam rancangan ini.
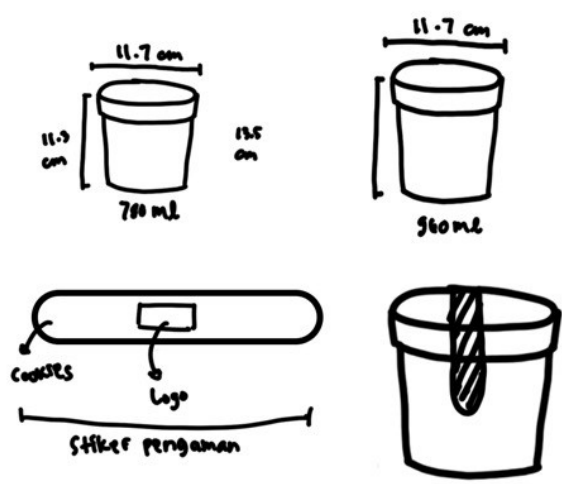

\section{Gambar 13. Rough Sketch Kemasan}

Dengan telah dipilihnya bentuk dan ukuran kemasan yang akan dirancang maka pada tahap ini dilakukannya perancangan pola kemasan. Pola kemasan pada paper bowl ini cukup sederhana karena hanya mempunyai 2 bagian yaitu tube dan penutup.

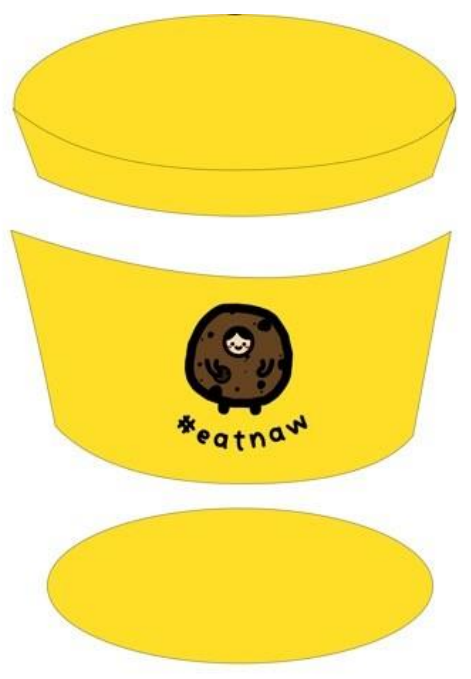

Gambar 14. Pola Kemasan

Hasil akhir yang berbentuk paper bowl yang mempunyai 2 ukuran yang akan dilengkapi dengan paper bag. Penggunaan paper bag memudahkan untuk pemilik dan pembeli mengirim dan menerima produk. Hal ini juga memudahkannya kemasan toples untuk ditumpuk, jika pembeliannya lebih dari satu. 


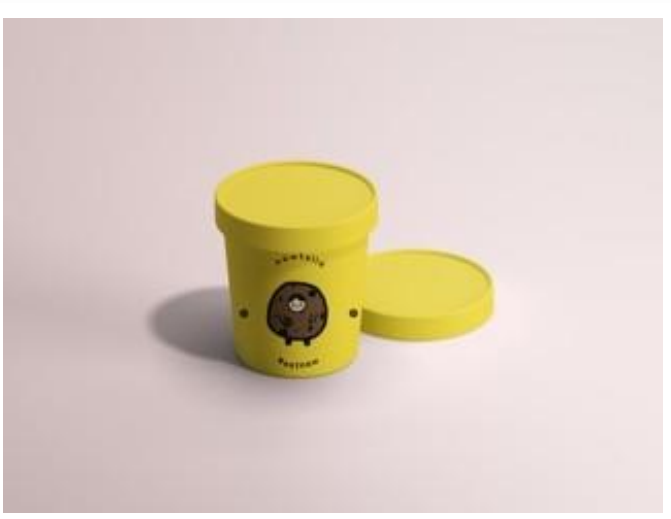

\section{Gambar 15. Final Kemasan Paper Bowl}

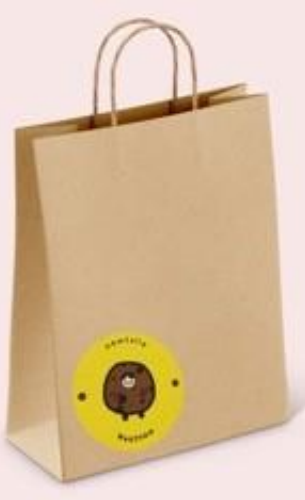

Gambar 16. Final Kemasan Paper Bag

\subsubsection{Buku Corporate Identity System (CIS)}

Corporate Identity System adalah buku yang berisikan tentang panduan dan aturan dalam penggunaan logo dan elemen identitas visual brand pada media yang diinginkan. Buku ini diperuntukan menjaga konsistensi brand sehingga nilai dan pesan yang ingin disampaikan oleh brand dapat diterima dengan efektif.

\section{Tabel 1. List Buku Corporate Identity System}

\begin{tabular}{|c|c|c|}
\hline 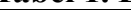 & & \\
\hline Chapter & Judul & Keterangan \\
\hline - & $\begin{array}{ll}\text { Table } & \text { of } \\
\text { Contents } & \end{array}$ & Daftar Isi \\
\hline - & Preface & $\begin{array}{l}\text { Kata Pengantar, tujuan } \\
\text { perancangan buku CIS }\end{array}$ \\
\hline \multirow[t]{6}{*}{1} & Logo Concept & Konsep logo \\
\hline & $\begin{array}{l}\text { Logo } \\
\text { Elements }\end{array}$ & Arti dari logo dan elemennya \\
\hline & $\begin{array}{l}\text { Logo } \\
\text { Construction }\end{array}$ & Logo dalam sistem grid \\
\hline & $\begin{array}{l}\text { Logo } \\
\text { Configuration } \\
\mathrm{S}\end{array}$ & $\begin{array}{l}\text { Cara pemilihan logo dengan } \\
\text { warna yang tepat }\end{array}$ \\
\hline & $\begin{array}{l}\text { Logo Size } \\
\text { Restrictions }\end{array}$ & $\begin{array}{l}\text { Minimum besaran } \\
\text { penggunaan logo dalam media } \\
\text { cetak maupun digital }\end{array}$ \\
\hline & $\begin{array}{l}\text { Minimum } \\
\text { Free Space }\end{array}$ & $\begin{array}{l}\text { Penggunaan ruang kosong di } \\
\text { area luar logo }\end{array}$ \\
\hline
\end{tabular}

\begin{tabular}{|c|c|c|}
\hline & Logo Usage & $\begin{array}{l}\text { Penggunaan logo dalam versi } \\
\text { warna, hitam, putih, dan } \\
\text { grayscale }\end{array}$ \\
\hline & $\begin{array}{l}\text { Incorrect } \\
\text { Logo Usage }\end{array}$ & $\begin{array}{l}\text { Penggunaan logo yang tidak } \\
\text { boleh dilakukan dan salah }\end{array}$ \\
\hline 2 & Color Pallete & $\begin{array}{l}\text { Arti dari warna perusahaan, } \\
\text { kode warna }\end{array}$ \\
\hline & Typography & Jenis font yang digunakan \\
\hline & Pattern & $\begin{array}{l}\text { Arti dan contoh penggunaan } \\
\text { elemen pattern }\end{array}$ \\
\hline \multirow[t]{2}{*}{3} & $\begin{array}{l}\text { Brand } \\
\text { Expression }\end{array}$ & $\begin{array}{l}\text { Aturan berupa ukuran, bahan, } \\
\text { finishing, dan contoh } \\
\text { corporate identity, stationary } \\
\text { dan packaging }\end{array}$ \\
\hline & $\begin{array}{l}\text { Photography } \\
\text { and Video }\end{array}$ & $\begin{array}{l}\text { Aturan dalam mengambil foto } \\
\text { dan video serta contoh. }\end{array}$ \\
\hline
\end{tabular}

Dari daftar data dan isi yang telah dibuat pada tabel di atas, perancang an buku akan menggunakan sistem grid yang bertujuan untuk mengatur jarak kolom antar kolom sehingga buku terlihat rapi dan konsisten.

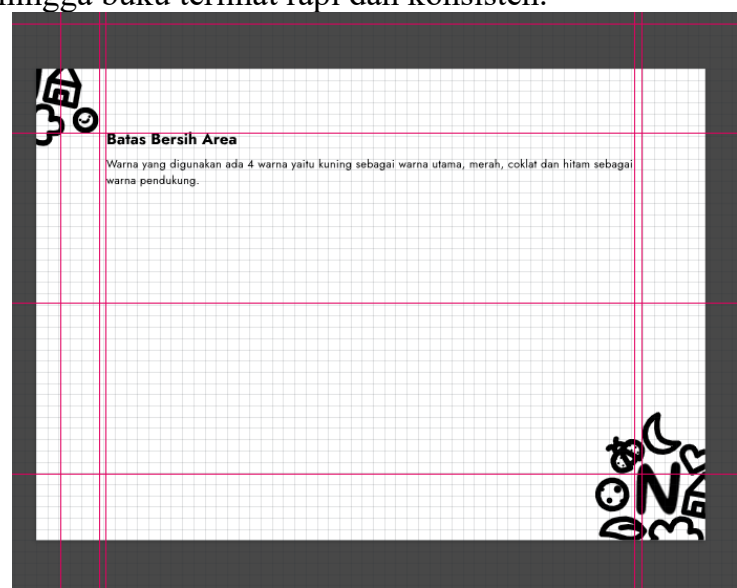

Gambar 17. Comprehensive Buku

Tahap final yang dilakukan adalah pencetakan buku CIS dengan isi yang sesuai dengan daftar isi yang dibuat sebelumnya.

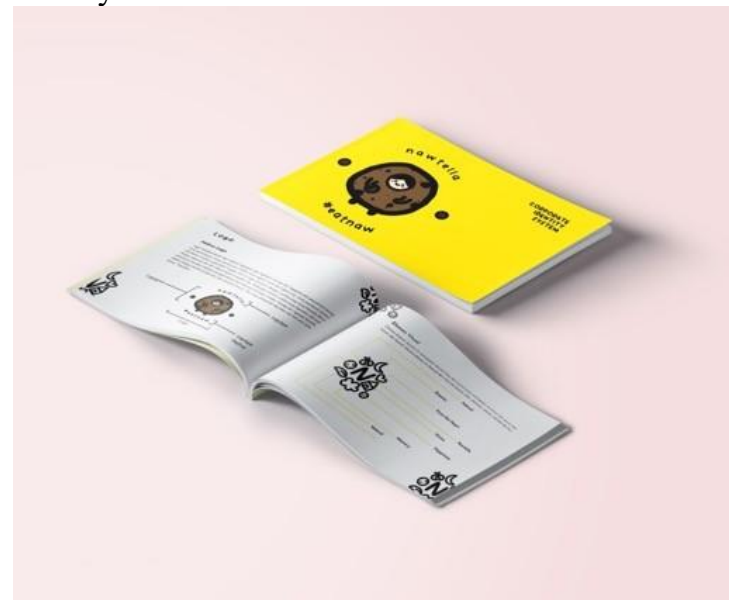

Gambar 18. Buku CIS

4.4.7 Fotografi 
Tahap fotografi bertujuan sebagai salah satu media promosi serta dijadikan sebagai media untuk menyampaikan pesan yang ingin disampaikan oleh brand seperti pembukaan batch baru atau open order. Sesi fotografi yang dilakukan dalam tahap ini menggunakan natural light, dengan background kain putih yang ditujukan untuk menonjolkan warna dan tekstur dari produk. Objek foto ditata dengan tujuan untuk menyampaikan kesan menyeluruh dari Nawtella. Selain produk dari Nawtella, digunakannya objek pendukung seperti segelas susu. Setelah dilakukannya sesi photo-taking, dilakukannya tahap editing. Tahapan ini dilakukan untuk menambahkan dan menyamaratakan waran sesuai dengan yang diinginkan. Proses yang dilakukan akan menggunakan software Adobe Photoshop.
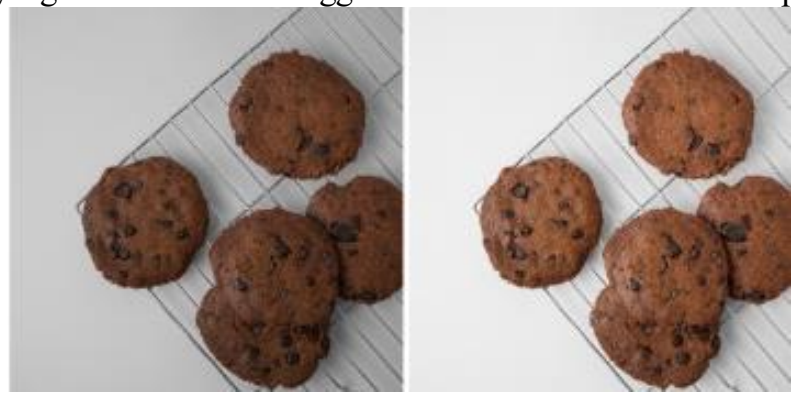

\section{Gambar 19. Proses Editing}

Setelah melalui tahap editing, hasil dari fotografi tersebut melalu proses retouch. Proses ini dilakukan untuk merapikan background serta penambahan produk (duplikasi) jika dirasa kurang. Tahap ini dilakukan dengan menggunakan software Adobe Photoshop.

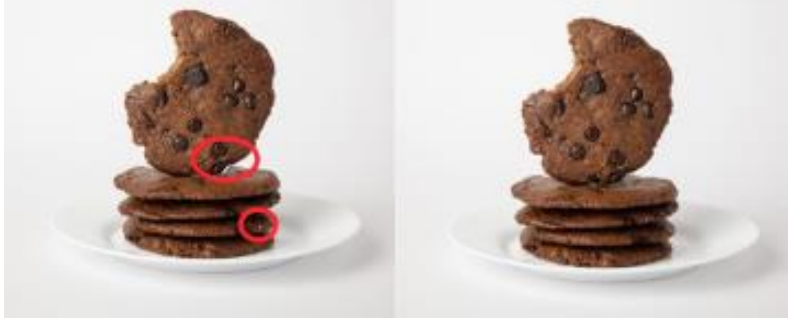

Gambar 20. Proses Retouching

\subsubsection{Feeds Instagram}

Seperti tahap pembuatan pembuatan daftar isi buku, tahap ini dilakukannya penyusunan konten apa saja yang akan dibuat. Konten-konten ini berupa foto produk serta video produk yang lalu diolah sehingga menghasilkan konten yang selaras dengan tujuan perancangan.

\section{Tabel 2. List Feeds Instagram}

\begin{tabular}{|l|l|l|}
\hline Jenis & Konten & Keterangan \\
\hline $\begin{array}{l}\text { Interaction } \\
\text { Post }\end{array}$ & $\begin{array}{l}\text { Ways to } \\
\text { Indulge } \\
\text { Cookies }\end{array}$ & $\begin{array}{l}\text { Cara-cara untuk menikmati } \\
\text { cookies }\end{array}$ \\
\cline { 2 - 3 } & $\begin{array}{l}\text { Sejarah } \\
\text { Cookies }\end{array}$ & Sejarah dari cookies \\
\cline { 2 - 3 } & $\begin{array}{l}\text { Tips } \\
\text { Menikmati } \\
\text { Cookies } \\
\text { Nawtella }\end{array}$ & $\begin{array}{l}\text { Cara untuk memakan cookies } \\
\text { dari Nawtella }\end{array}$ \\
\hline
\end{tabular}

\begin{tabular}{|c|c|c|}
\hline \multirow[t]{12}{*}{$\begin{array}{l}\text { Promotion } \\
\text { Post }\end{array}$} & $\begin{array}{l}\text { Motion } \\
\text { Open } \\
\text { Batch }\end{array}$ & $\begin{array}{l}\text { Announcement pembukaan } \\
\text { batch order }\end{array}$ \\
\hline & $\begin{array}{l}\text { Motion } \\
\text { Tagline } \\
\text { \#eatnaw }\end{array}$ & $\begin{array}{l}\text { Tagline \#eatnaw dengan efek } \\
\text { typewriter }\end{array}$ \\
\hline & $\begin{array}{l}\text { Stop } \\
\text { Motion } \\
\text { Open } \\
\text { Batch }\end{array}$ & $\begin{array}{l}\text { Annoucement pembukaan batch } \\
\text { order }\end{array}$ \\
\hline & $\begin{array}{l}\text { Stop } \\
\text { Motion } \\
\text { Cookies } \\
\text { Eaten }\end{array}$ & Cookies yang dimakan \\
\hline & $\begin{array}{l}\text { Stop Foto } \\
\text { Produk } \\
\text { Close Up }\end{array}$ & Foto cookies detail \\
\hline & $\begin{array}{l}\text { Medium- } \\
\text { shot Foto } \\
\text { Produk }\end{array}$ & $\begin{array}{l}\text { Foto cookies terlihat } \\
\text { background dan piringnya serta } \\
\text { gelas tetapi diambil dari atas }\end{array}$ \\
\hline & $\begin{array}{l}\text { Medium- } \\
\text { shot Foto } \\
\text { Produk }\end{array}$ & $\begin{array}{l}\text { Foto cookies terlihat } \\
\text { background, piring serta gelas }\end{array}$ \\
\hline & $\begin{array}{l}\text { Ilustrasi } \\
\text { dan foto } \\
\text { produk }\end{array}$ & $\begin{array}{l}\text { Foto cookies diberi sebuah } \\
\text { ilustrasi dari logo Nawtella }\end{array}$ \\
\hline & $\begin{array}{l}\text { Ilustrasi } \\
\text { dan foto } \\
\text { produk }\end{array}$ & $\begin{array}{l}\text { Foto cookies diberi sebuah } \\
\text { ilustrasi dari logo Nawtella }\end{array}$ \\
\hline & $\begin{array}{l}\text { Story } \\
\text { Logo } \\
\text { Nawtella }\end{array}$ & Motion logo Nawtella \\
\hline & $\begin{array}{l}\text { Story } \\
\text { Stacking } \\
\text { Cookies }\end{array}$ & Video cookies yang disusun \\
\hline & $\begin{array}{l}\text { Story We } \\
\text { Are Back }\end{array}$ & $\begin{array}{l}\text { Video berisikan tentang } \\
\text { informasi telah dibukanya } \\
\text { kembali usaha Nawtekka }\end{array}$ \\
\hline
\end{tabular}

Konten-konten yang akan dirancang dan dimuat dalam laman Instagram Nawtella akan berbentuk foto dan video. Foto dan video akan digabungkan dengan elemen visual seperti teks dan ilustrasi. Pembuatan konten berupa foto dan video ini dibuat agar laman Instagram tidak membosankan. Pada proses perancangan konten, perancang akan menggunakan software berupa Adobe Photoshop, Adobe Illustrator dan Adobe After Effects.

Pembuatan konten-konten Nawtella dirancang untuk memudahkan audiens untuk mengingat brand, sehingga didalam setiap kontennya dimasukkannya pattern yang telah dibuat serta nama dari brand. Penggabungan grafis, foto, dan tcxt dalam pembuatan kontennya juga ditujukan agar tidak terlihat membosankan. 


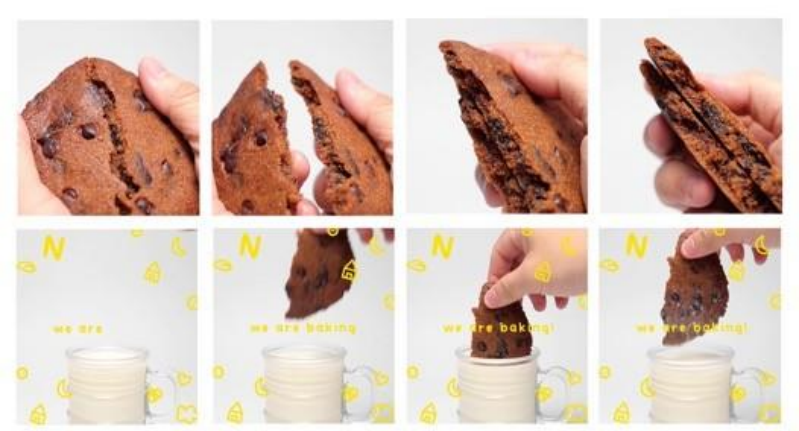

Gambar 21. Hasil Konten "We Are Baking"

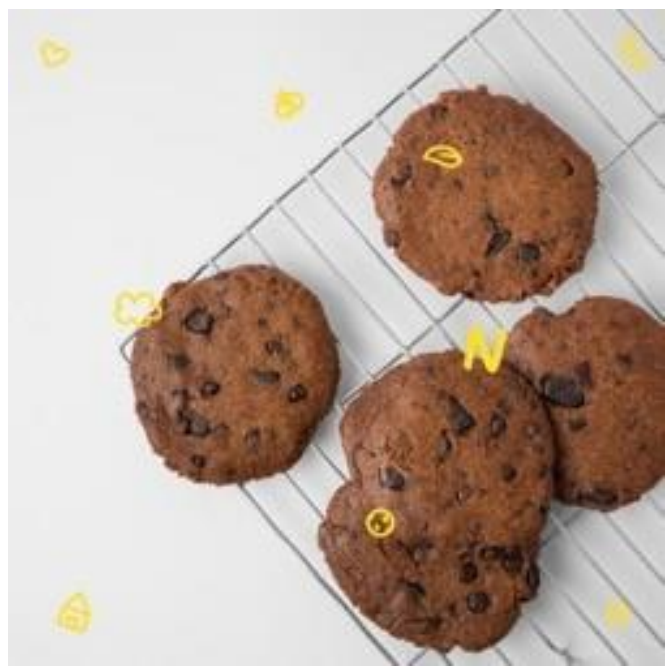

Gambar 22. Hasil Konten Produk Close-Up

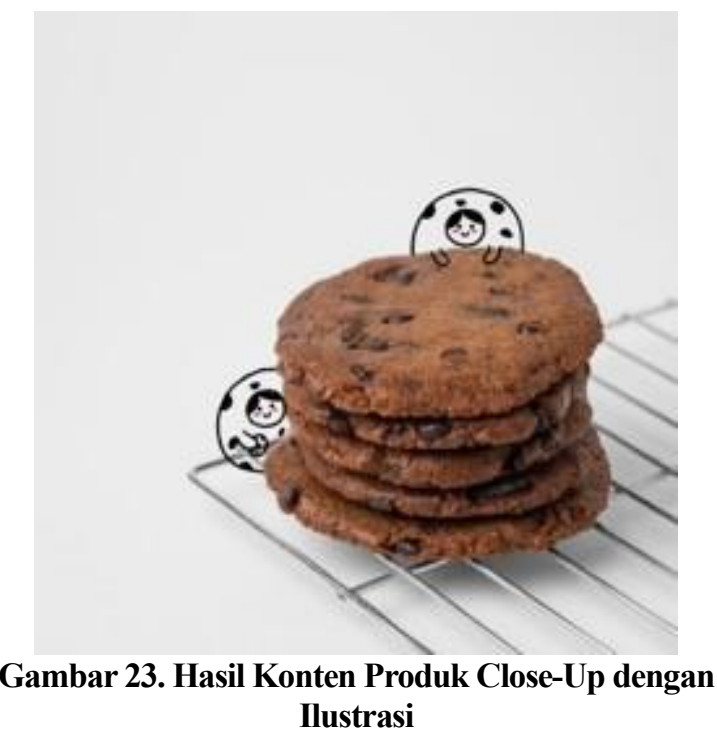

Setelah dilakukannya seluruh tahapan dari perancangan ini, hasil akhirnya dipamerkan secara online melalui media Instagram dengan format multiple post berjumlah 10 konten. Konten tersebut berisikan logo Nawtella, profil dari Nawtella, arti dari logo, sketsa kasar dari logo, tipografi yang digunakan Nawtella, mock up dari buku CIS, kemasan, 1 foto produk, dan 2 video.
Menjadinya UMKM sebagai salah satu instrumen penting dalam pergerakan perekonomian Indonesia membuat peningkatan industri UMKM-UMKM saat ini. Hal ini dapat terlihat pada banyaknya kedai kecil seperti cafe dan angkringan. Pertumbuhan industri ini juga terjadi di dunia digital juga yang banyaknya para pengusaha-pengusaha menjual barang dan jasanya secara daring.

Nawtella merupakan salah satu UMKM yang bergerak di industri makanan dan minuman yang ada di Kota Jakarta Barat. Nawtella tidak memiliki brand identity yg menonjol sehingga brand masih kurang dikenali oleh masyarakat. Maka dari itu, diperlukan re-branding untuk meningkatkan brand awareness serta menarik target pasar yang diinginkan.

Perancangan ini disusun dengan menerapkan metode kualitatif yang proses pengumpulan datanya dilakukan melalui wawancara, studi pustaka dan dokumentasi. Data-data yang didapatkan kemudian dianalisis dengan teknik analisis SWOT yang akan menghasilkan matriks SWOT. Matriks SWOT ini akan membantu proses apa saja yang harus dilakukan oleh Nawtella.

Re-branding yang dilakukan adalah penambahan mascot serta penggantian warna kuning yang dapat lebih menarik perhatian target pasar yang dituju. Identitas visual dirancang dengan gaya desain yang sederhana dan natural. Identitas visual Nawtella dilengkapi dengan logogram, logotype, tagline dan pattern. Warna yang digunakan pun bertujuan untuk menarik perhatian audiens. Warna tersebut adalah warna kuning, merah, coklat dan hitam.

Audiens yang dituju oleh Nawtella adalah anak-anak muda yang kebanyakan dari mereka mempunyai akses ke semua media sosial termasuk Instagram sehingga Nawtella menjadikan media promosi digitalnya di Instagram. Selain itu, Instagram memudahkannya komunikasi 2 arah antara brand dengan audiensnya.

Hasil akhir dari perancangan re-branding ini adalah logo, buku Corporate Identity System (CIS), media promosi berbentuk konten untuk laman Instagram yaitu sebanyak 15 post terdiri dari 8 foto produk, 3 story, 2 stop-motion, 2 motion grafis. Semua konten dirancang dengan penggabungan elemen teks, foto, ilustrasi dan gambar grafis. Elemen desain pendukungnya adalah packaging yang berupa paper bag dan paper bowl lalu stationery dengan thank you card, business card dan sticker.

\section{DAFTAR PUSTAKA}

BPS DKI JAKARTA. (2016). "Potensi Usaha Mikro Kecil DKI Jakarta".

https://jakarta.bps.go.id/publication/2018/12/31/77fd4d 04e42bb0d131ff2baf/potensi-usaha-mikro-kecil-

provinsi-dki-jakarta.html. Diakses pada 3 September 2020.

Fatimah, F.N.A.D., 2016. Teknik Analisis SWOT. Anak Hebat Indonesia.

Halim, J.M., Hagijanto, A.D. dan Maer, B.D.A., 2019. Perancangan Brand Identity E-Commerce" Greater Good". Jurnal DKV Adiwarna, 1(14), p.10.

Haryanti, D.M dan Isniati Hidayah. 2018. Potret UMKM Indonesia: $\mathrm{Si}$ Kecil yang Berperan Besar. https://www.ukmindonesia.id/baca-artikel. Diakses pada 3 September 2020

\section{KESIMPULAN}


Indika, D.R. dan Jovita, C., 2017. Media Sosial Instagram Sebagai Sarana Promosi Untuk Meningkatkan Minat Beli Konsumen. Jurnal Bisnis Terapan, 1(01), pp.25-32.

LD FEB UI. 2018. Dampak GOJEK Terhadap Perekonomian Jabodetabek pada Tahun 2018. https://ldfebui.org/wpcontent/uploads/2019/03/LDUI-Dampak-GOJEKpada-Perekonomian-Jabodetabek-2018.pdf. Diakses pada 3 Sepetmber 2020

Seloadji, H., Artawan, C.A. dan Wahyudi, A.T., 2018. Perancangan Corporate Identity VIP Bakery Tulungagung. Jurnal DKV Adiwarna, 1(12), p.10.
Sianturi, N.E., 2020. Perancangan Desain Logo Toko Super Bakery dan Pengaplikasiannya. Proporsi: Jurnal Desain, Multimedia dan Industri Kreatif, 4(1), pp.8092.

Tandio, E., Adib, A. dan Suhartono, A.W., 2013. Perancangan Logo dan Desain Kemasan Untuk Dhisti Cookies Sebagai Camilan di Kota Solo. Jurnal DKV Adiwarna, 1(2), p.10.

Wheeler, A. 2013. Designing Brand Identity: Fourth Edition, John Willey \& Sons, Inc. Hoboken, New Jersey. 